\title{
TU/e EmonONEN

\section{The determination of aldehydes in the exhaust gases of LPG fuelled engines}

\section{Citation for published version (APA):}

Rutten, G. A. F. M., Burtner, C. W. J., Visser, H., \& Rijks, J. A. (1988). The determination of aldehydes in the exhaust gases of LPG fuelled engines. Chromatographia, 26(1), 274-280. https://doi.org/10.1007/BF02268166

DOI:

10.1007/BF02268166

Document status and date:

Published: 01/01/1988

\section{Document Version:}

Publisher's PDF, also known as Version of Record (includes final page, issue and volume numbers)

\section{Please check the document version of this publication:}

- A submitted manuscript is the version of the article upon submission and before peer-review. There can be important differences between the submitted version and the official published version of record. People interested in the research are advised to contact the author for the final version of the publication, or visit the $\mathrm{DOI}$ to the publisher's website.

- The final author version and the galley proof are versions of the publication after peer review.

- The final published version features the final layout of the paper including the volume, issue and page numbers.

Link to publication

\section{General rights}

Copyright and moral rights for the publications made accessible in the public portal are retained by the authors and/or other copyright owners and it is a condition of accessing publications that users recognise and abide by the legal requirements associated with these rights.

- Users may download and print one copy of any publication from the public portal for the purpose of private study or research.

- You may not further distribute the material or use it for any profit-making activity or commercial gain

- You may freely distribute the URL identifying the publication in the public portal.

If the publication is distributed under the terms of Article 25fa of the Dutch Copyright Act, indicated by the "Taverne" license above, please follow below link for the End User Agreement:

www.tue.nl/taverne

Take down policy

If you believe that this document breaches copyright please contact us at:

openaccess@tue.nl

providing details and we will investigate your claim. 


\title{
The Determination of Aldehydes in the Exhaust Gases of LPG Fuelled Engines
}

\author{
G.A. Rutten $1 /$ C.W. J. Burtner ${ }^{2} /$ H. Visser $2 /$ J.A. Rijks ${ }^{1 *}$
}

Eindhoven University of Technology, ${ }^{1}$ Dept. Chemical Technology, Laboratory for Instrumental Analysis, ${ }^{2}$ Dept. Mechanical Engineering, Section Product Design and Construction, P. O. Box 513, NL-5600 MB Eindhoven, The Netherlands

Key Words
Capillary gas chromatography
2,4-dinitrophenylhydrazones
Aldehydes and carbonyl compounds
Automobile exhaust gas
Liquefied petroleum gas

\section{Summary}

The exhaust gas of a LPG fuelled engine is drawn through two bubblers in series in an ice bath, and filled with saturated 2,4-dinitrophenylhydrazine in $2 \mathrm{M} \mathrm{HCl}$. After heating the derivatives are extracted with toluene-cyclohexane and $1 \mu \mathrm{l}$ samples injected "on-column" on a OV1 capillary column. Using an FID the lower limit of detection is $15-18 \mathrm{pg}$ for formaldehyde (about $8-10$ ppbv for a $16 /$ exhaust sample). Taking the blank into account, the limit is about 40 ppbv.

The exhaust gases of a LPG-fuelled engine contain formaldehyde, acetaldehyde, propionaldehyde, acrolein and acetone. Carbonyl compounds of more than $3 \mathrm{C}$-atoms were not found in detectable amounts. The engine was rund under stoichiometric, lean and rich air/fuel conditions. Under rich conditions the concentrations of the aldehydes were: formaldehyde $2.8 \mathrm{ppm}$, acetaldehyde $1.3 \mathrm{ppm}$, propionaldehyde $0.06 \mathrm{ppm}$, acrolein $0.03 \mathrm{ppm}$, acetone $0.17 \mathrm{ppm}$; under stoichiometric conditions: $4.5,1.6,0.10,0.03$ and $0.18 \mathrm{ppm}$ respectively; under lean conditions $17.0,2.9,0.13,0.07$ and $0.27 \mathrm{ppm}$ respectively. These figures demonstrate the necessity of measuring aldehydes in exhaust gases of LPG-fuelled engines.

\section{Introduction}

Whereas industrial pollution has decreased during recent years, automotive emissions continue to contribute signifi. cantly to air pollution in the Netherlands (see Table 1). For some pollutants this contribution is still increasing.

The use of LPG (liquified petroleum gas) offers certain advantages and can give low exhaust emissions [1]. The lean misfire limit of an LPG-fuelled engine extends well beyond the limit with gasoline and can be used to achieve low emission levels of regulated pollutants (hydrocarbons, oxides of nitrogen, carbon monoxide). However, the problem of obtaining a suitable LPG engine with proper carburation and ignition design, hinders full utilization of LPG as a "clean" motor fuel. Moreover, the use of LPG as a motor fuel depends largely on the fuel tax policy of the various countries.

Increasing use of LPG-fuelled cars in the Netherlands (Table II) warrants further research in this field. Since 1981 a research program has been carried out at the Department of Mechanical Engineering of Eindhoven University of Technology to achieve more efficient use of LPG. Among the aims is the reduction of pollution. In cooperation with the Laboratory of Instrumental Analysis the relationship between the combustion conditions and the composition of the exhaust gases is being investigated.

It is reported in the literature that for LPG-fuelled cars the exhaust emission of almost all harmful components (not-

Table I. Contribution of total road traffic and contribution of passenger cars to emission of air pollutants in the Netherlands.

\begin{tabular}{|lcc|}
\hline & $\begin{array}{c}\text { Total road traffic } \\
\%\end{array}$ & $\begin{array}{c}\text { Passenger cars } \\
\%\end{array}$ \\
\hline $\mathrm{CO}$ & 74 & 82 \\
$\mathrm{NO}_{\times}$ & 50 & 63 \\
$\mathrm{SO}_{2}$ & 4 & 17 \\
Parafins & 28 & 70 \\
Olefins & 72 & 74 \\
Aromatics & 64 & 80 \\
Benzene & 78 & 80 \\
Aldehydes & 66 & 58 \\
Lead & 80 & 91 \\
\hline
\end{tabular}

Table II. Market share in the Netherlands of various fuels by passenger cars (based on mileage), 1984.

\begin{tabular}{|lc|}
\hline Fuel & $\%$ \\
\hline Gasoline & 73 \\
Diesel & 10 \\
LPG & 17 \\
\hline
\end{tabular}


ably carbon monoxide, polycyclic aromatic hydrocarbons and aromatics) is an order of magnitude lower than for gasoline fuelled cars, except for $\mathrm{NO}_{x}$, which was about the same level, and for aldehydes, which were about twice as high [2].

Carbonyl compounds, particularly aldehydes, are toxic: they irritate the eyes and the mucous membranes of nose and lungs. Moreover, formaldehyde and acrolein are suspected carcinogens. Aldehydes and ketones also play a central role in photochemical smog formation since they are an important source of free radicals. Furthermore, they are the direct precursors of peroxyacylnitrates.

In view of the forgoing and the relative scarcity of data on emission of aldehydes by (LPG fuelled) cars, we concentrated on the measurement of aldehydes, the development of a sampling system and an analytical procedure for the determination of aldehydes in the exhaust gases of a test engine run under various combustion conditions.

\section{Occurrence and Measurement of Aldehydes in Exhaust Cases of Internal Combusion Engines}

Aldehydes have long been recognized as constituents of automobile exhaust gases. However, access to all measurements which have been performed in various countries by many different organizations is difficult. The published data in addition, mainly originate in the USA. Problems also arise in the interpretation of the results from the variety of sampling techniques, testing methods, engines, fuels and combustion conditions and valid comparisons are therefore difficult. In general, [3-15] the concentration of aldehydes in the exhaust gases of petrol driven cars is $10-70$ ppmv although catalytic exhaust control reduces this to about 1 ppmv or less. For diesel cars concentrations tend to be lower, whereas oxygenated fuels give higher concentrations. Data on LPG-fuelled engines are scarce $[1,2,17,18]$. In one study, however, the same cars were fuelled alternatively with LPG and gasoline [19]: the emission of aldehydes from the LPG compared unfavourably with gasoline.

Exhaust gas measurements can be expressed either as concentration units (e.g. $\mathrm{mg} / \mathrm{m}^{3}, \mathrm{mmol} / \mathrm{m}^{3}, \mathrm{ppm}$ ) or as emission rates from the vehicle (e.g. $\mathrm{mg} / \mathrm{km}, \mathrm{mg} / \mathrm{l}$ fuel). To relate the measurements to pollution by motor traffic, emission rate units are proper: the vehicle chould be subjected to a simulated driving cycle on a chassis dynamometer and a dilution tunnel should be used to simulate the atmospheric dilution process. In our case, however, the test engine is run at constant rpm under stable, stationary conditions. Samples can, therefore, simply be taken directly from the exhaust manifold and the results expressed as concentration units.

Aldehydes in the exhaust gas cannot be measured directly, they must be trapped and concentrated before chromatographic analysis. Moreover, aldehydes are reactive compounds and preferably are converted into stable derivatives. Mostly, 2,4-dinitrophenylhydrazine (DNPH) is used to form 2,4-dinitrophenylhydrazones. The aldehydes can be trapped in small scrubbers, bubblers or impingers with an acidified aqueous $[3-7,12,13,15]$ or acetonitrile [8$11,14]$ solution of DNPH, through which the exhaust gas is drawn: the aldehydes are trapped in the solution simultaneously forming 2,4-dinitrophenylhydrazones.

Aldehydes can also be trapped on adsorbents impregnated with DNPH. While cartridges offer greater versatility, especially in mobile and outdoor sampling [20-25], we preferred liquid bubblers, because they require less preparation, involve less handling and risk of contamination of the reagents and because our measurements take place indoors in a single test engine cell. Indeed, cartridges have seldom been used for exhaust gas sampling [26].

The 2,4-dinitrophenyl-hydrazones can be extracted and analyzed by GC or LC. When an acetonitrile solution is used, the contents of the bubbler can be injected directly on the LC. Earlier GC experience with packed columns, which lacked sufficient separation power, sensitivity and inertness, led to the development of HPLC methods $[6,13$, 27, 28]. Although HPLC analysis of DNPH-derivatives offers distinct advantages, such as low temperature, rather specific UV detection and normal sample handling and injection techniques, resolution is not high and complete separation of all important carbonyls of automobile exhaust can only be achieved by extensive eluent programming, resulting in long analysis times. Capillary GC, however, offers high resolution and potentially fast analysis [22]; sensitive and specific detection (EC $[7,29]$ or NDP detector, respectively) and easy coupling to a mass spectrometer [30] $(\mathrm{NICl}$ is an excellent and very sensitive ionization technique for 2,4-dinitrophenylhydrazones). Problems with injection and column activity have been overcome by the use of on-column injection and high-temperature silylation.

\section{Method and Materials}

The aldehydes and ketones are trapped in small bubblers, usually in several in series, filled with saturated DNPH in $2 \mathrm{M} \mathrm{HCl}$, simultaneously forming the corresponding hydrazones:

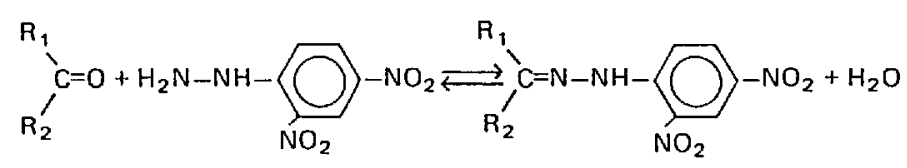

In most cases a mixture of syn-and anti-isomers is formed. The isomerization of 2,4-dinitrophenylhydrazones has already received attention [31-33]: isomerization is enhanced under acidic conditions, e.g., by the use of solvents containing traces of acids. Formaldehyde, symmetrical ketones, unsaturated and aromatic aldehydes and ketones, and compounds with bulky groups, form only one derivative.

The trapping and derivatization of aldehydes in DNPH solutions has been studied in some detail, especially for formaldehyde and acetaldehyde [34-36]. It requires an acid catalyst. Initially, the reaction rate increases with decreasing $\mathrm{pH}$, but too high $\mathrm{H}^{+}$concentrations lead to increased salt formation of the DNPH, which reduces the 
reaction rate and adversely shifts the equilibrium. An optimum $\mathrm{pH}$ of about 3.0 and $2.0 \simeq 2.5$ was reported for formaldehyde and acetaldehyde, respectively.

The reaction is reversible: from published data $[27,34-$ 37 ] one can deduce equilibrium constants at room temperature of the order of $2 \sim 8.10^{-5}$ for the lower aldehydes. At lower temperatures the equilibrium is shifted towards hydrazone formation. From these figures it follows that a large excess of reagent, say $>150$-fold, should be present (a saturated solution of DNPH in $2 \mathrm{M} \mathrm{HCl}$ is about $2.10^{-2}$ M).

When large quantities of aldehydes are involved, the hydrazones, which are scarcely soluble in the aqueous reagent, precipitate, the equilibrium shifts towards derivative formation and the reaction is almost quantitative. A similar effect can be obtained by the addition of an organic solvent to the reaction vessel. Positive as well as negative results have been reported $[21,27,37,38]$. The addition seems beneficial mainly for the $\mathrm{C}_{2}-\mathrm{C}_{4}$ aldehydes and benzaldehyde. For formaldehyde the results are rather indifferent and they are even clearly unfavourable for the higher aldehydes. Probably the formaldehyde-hydrazone dissolves too well in the aqueous phase, whereas the higher aldehydes dissolve, underivatized, too freely in the organic phase.

The trapping efficiency depends on the diffusivities of the aldehydes, the turbulence of gas and liquid, the contact time and area between gas and liquid, the dissolution of and the rate of derivatization of the aldehydes. Generally, bubblers are efficient up to gas flows of about $11 \mathrm{~min}^{-1}$. [4] which, in view of the expected concentrations in exhaust gases will be ample in our work. The difference between fritted or plain bubblers is important in marginal cases only. The solubility of lower aldehydes, notably formaldehyde and acetaldehyde is well documented [3941]. The solubilities increase significantly at lower temperatures: in this respect cooling of the samplers to $0^{\circ} \mathrm{C}$ is very beneficial towards trapping efficiencies. However, on cooling the rate of derivatization drops. Roughly, the various authors agree on reaction times of about $1 \mathrm{hr}$ at room temperatures to $2 \mathrm{hrs}$ at $0^{\circ} \mathrm{C}$, without much difference between the individual aldehydes. Since these values are about the same as the expected sampling time, the effects of reaction rate on the trapping efficiency cannot be easily assessed.

In practice, widely varying trapping efficiencies (mostly however, between 85-100\%/ have been reported. Generally, acetaldehyde and benzaldehyde seem to present more difficulties than formaldehyde. However, two bubblers in series give very satisfactory results.

\section{Reagents}

2,4-dinitrophenylhydrazine, DNPH (pro analysi, E. Merck, Darmstadt, FRG) was dried over silica gel, recrystallized twice from carbonyl-free ethylacetate, and kept in a desiccator over concentrated sulphuric acid. All solvents (ethylacetate, ethanol, cyclohexane, toluene; all pro analysi, E. Merck, Darmstadt, FRG) and water (from a Millipore $\mathrm{Q}$ apparatus) were made carbonyl-free by refluxing over DNPH and concentrated sulphuric acid (for ethylacetate also some acetic acid anhydride). Then they were carefully distilled aver an efficient column. $2 \mathrm{M}$ Hydrochloric acid was prepared from E. Merck, "titrisol", p.a. and carbonyl free water.

A saturated solution of DNPH in $2 \mathrm{M} \mathrm{HCl}$ was used for sampling. The solution was kept at $4^{\circ} \mathrm{C}$. For sampling, solutions not older than 4 weeks were used. Immediately before sampling $25 \sim 30 \mathrm{ml}$ of the DNPH solution were placed in the bubblers and extracted with $10 \mathrm{ml}$ portions of cyclohexane/toluene $5: 1 \mathrm{v} / \mathrm{v}$ three times, in order to remove carbonyl impurities. For quantitation 2,4-dinitrophenylhydrazone standards of formaldehyde, acetaldehyde, propionaldehyde, acrolein, acetone and cyclopentanone (all Fluka A.G., Buchs, Switzerland; highest purity available) were prepared according to Shriner [42], except for acetaldehyde, which was prepared from cooled, saturated DNPH $/ 2 \mathrm{M} \mathrm{HCl}$ solution. The hydrazones were recrystallized twice from carbonyl-free ethanol or ehtanol/water, and kept over concentrated sulphuric acid. Standard solutions were prepared in cyclohexane/toluene $5: 1 \mathrm{v} / \mathrm{v}$ and a crystal of DNPH was added to each flask [33].

\section{Gas Chromatography}

After extraction of the sampling solution with cyclohexane / toluene (vide infra), the derivatives are analyzed by capillary GC. A Carlo Erba Mega, model 5300, provided with an on-column injector (carrier gas: $\mathrm{He}, 150 \mathrm{kPa}$ ) and FID, was used with a $25 \mathrm{~m} \times 0.32 \mathrm{~mm}$ i.d. fused-silica column, coated with $0.52 \mu \mathrm{m}$ layer of cross-linked methylsilicone (Hewlett Packard, Ultraperformance column, Avondale, PA, USA), and an uncoated, thoroughly deactivated $1.3 \mathrm{mX}$ $0.3 \mathrm{~mm}$ i.d. fused-silica retention gap as inlet section. $1 \mu \mathrm{l}$ of extract or other standard solution was injected on-column at an oven temperature of $90^{\circ} \mathrm{C}$, while the secondary cooling was on for $1 \mathrm{~min}$.

After trials the following temperature program was established: $1 \mathrm{~min} 90^{\circ} \mathrm{C}, 20^{\circ} \mathrm{Cmin}^{-1}$ to $170^{\circ} \mathrm{C}, 25 \mathrm{~min} 170^{\circ} \mathrm{C}$, $3^{\circ} \mathrm{C} \mathrm{min}^{-1}$ to $230^{\circ} \mathrm{C}$. Under these conditions complete separation of propionaldehyde, acetone and acrolein is obtained (see Fig. 1). The peaks were integrated and quantified with a Nelson Analytical, series 3000, chromatography data system (Nelson Analytical Inc., Cupertino, CA, USA).

\section{Sampling and Analysis}

\section{Engine and Operation}

During testing the engine, a Ford 4-cylinder configuration, displacement $1600 \mathrm{cc}$, was operated under steady conditions at a speed of $2450 \mathrm{rpm}$, under partial load (estimated power $12 \mathrm{HP}$ ). The LP gas was commercial grade and was fed to the engine using a Vialle, type $C 4$, vaporizer system (Vialle Autogassystemen, Son, NL). Samples were taken directly from the exhaust manifold. Hydrocarbons (as $\mathrm{C}_{6} \mathrm{H}_{14}$ ), nitric oxide (NO), carbon monoxide and carbon dioxide were measured using NDIR, oxygen using paramagnetic detection (all analyzers Hartmann \& Braun A.G., Frankfurt, FRG). 


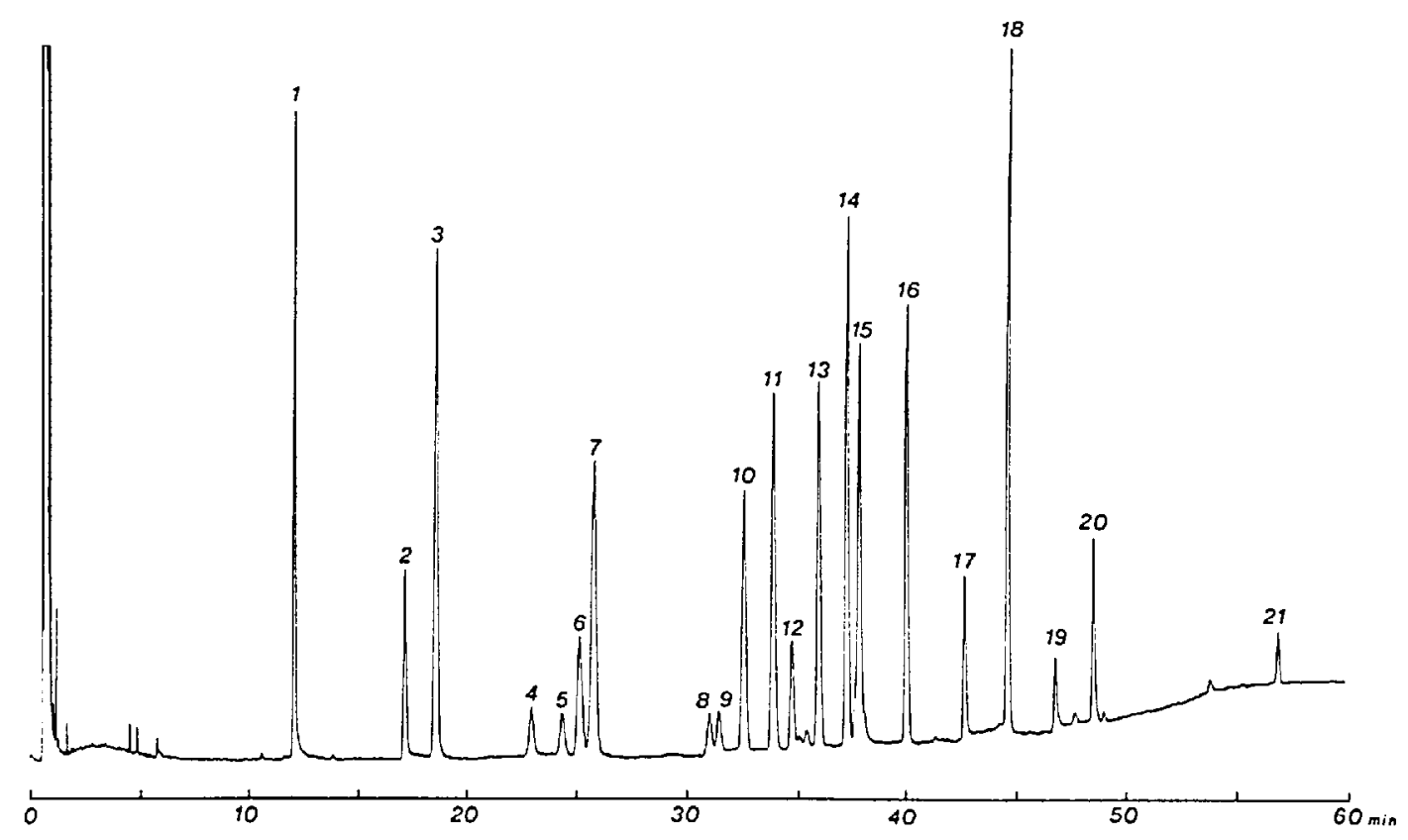

Fig. 1

Standard mixture of aldehydes and ketones (for GC conditions see text). Peaks: $1=$ formaldehyde; $2=$ acetaldehyde (s); 3 = acetaldehyde (a): 4 = propionaldehyde; $5=$ acetone; $\mathbf{6}=$ acrolein; $7=$ propionaldehyde (a); 8 = butyraldehyde (s); $9=$ butanone $(\mathrm{s}) ; 10=$ butanone $(\mathrm{a}) ; 11=$ butyraldehyde $(\mathrm{a}) ; 12=$ iso-valeraldehyde (a) : $13=2$-methyl-3-butanone: $14=$ iso-valeraldehyde (s); $15=$ crotonaldehyde + valeraldehyde (s); $16=$ valer . aldehyde (a) $; \mathbf{1 7}=$ hexanal $(\mathrm{s}) ; \mathbf{1 8}=$ hexanal $(\mathrm{a}) ; 19=$ heptanal $(\mathrm{s}) ; \mathbf{2 0}=$ heptanal $(\mathrm{a}) ; \mathbf{2 1}=$ benzaldehyde.

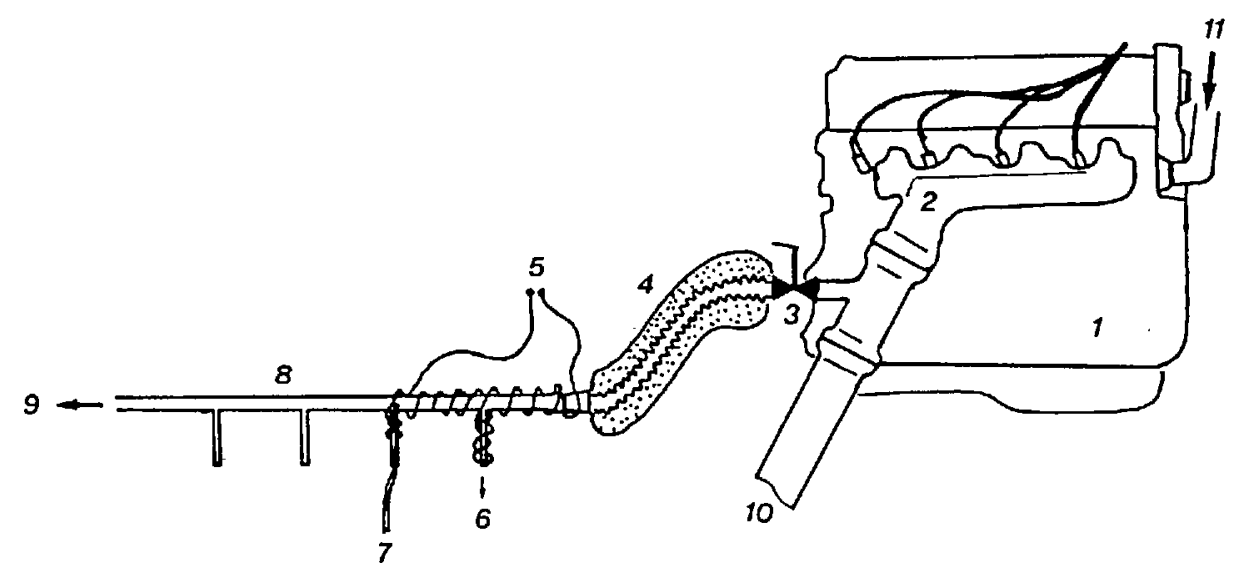

Fig. 2

Engine and exhaust configuration. 1 =engine; 2 = exhaust manifold; $\mathbf{3}=$ valve; $\mathbf{4}=$ isolated flexible stainless steel tubing; $\mathbf{5}=$ heating wire; $\mathbf{6}=$ to sampling train; $7=$ thermocouple; $8=$ glass sampling manifold; $9=$ to pump $(2 \sim 3 \mathrm{l} / \mathrm{min}) ; 10=$ to exhaust vent system; $11=$ coolant,

For aldehyde sampling, exhaust gases were taken directly at the end of the exhaust manifold and channelled through a thermally isolated flexible stainless steel tube to a heated glass sampling manifold (see Fig. 2).

Temperatures in the sampling manifold were kept above $100^{\circ} \mathrm{C}$ by means of electrical heating wire, to prevent condensation of water and polymerization of the aldehydes.

\section{Sampling}

The bubblers $(50 \mathrm{ml}$; length $12 \mathrm{~cm} \times 2.4 \mathrm{~cm}$ i.d.), provided with fritted inlets, are filled with $25-30 \mathrm{ml}$ DNPH solution and then extracted with $3 \times 10 \mathrm{ml}$ portions of cyclohexane/ toluene (see section 'reagents'). The setup consists of three bubblers in series of which the first two are filled with the DNPH solution, the third, acting as a safety bottle, with distilled water (Fig. 3). Exhaust gas was drawn at a rate of about $0.3 \sim 0.41 \mathrm{~min}^{-1}$ through the bubblers. During sampling the bubblers are placed in an ice bath. After sampling the bubblers are well stoppered and refrigerated until analysed. 


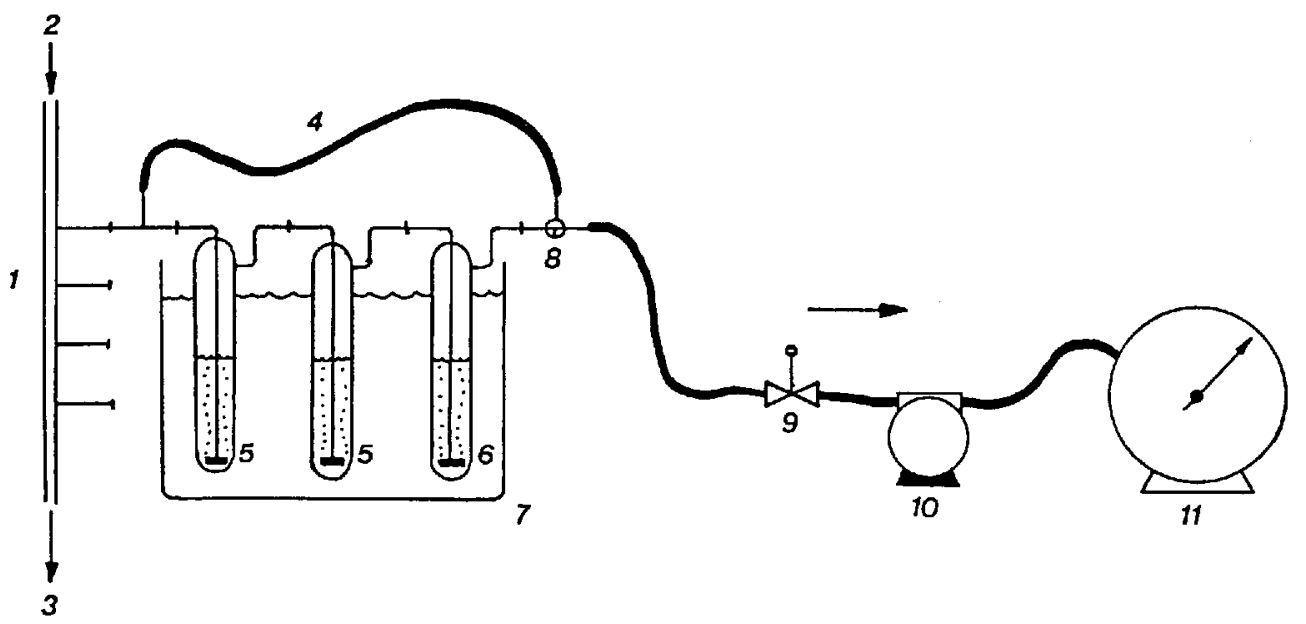

Fig. 3

Sampling train configuration. 1 = glass sampling manifold; $2=$ from exhaust manifold; $3=$ to pump $(2 \sim 31)$ $\min ) ; 4=$ by-pass; $5=$ sampling bubblers; $6=$ safety bubbler; $7=$ ice bath $\left(0^{\circ} \mathrm{C}\right) ; 8=$ three-way stopcock; $9=$ fine needle valve; 10 pump; $11=$ wet gas meter.

Table III. Minimum detectable amounts.

\begin{tabular}{|c|c|c|c|c|c|}
\hline & \multirow{3}{*}{$\begin{array}{c}\text { GC } \\
\text { limit } \\
\text { (as free aldehyde) } \\
\rho g\end{array}$} & \multicolumn{4}{|c|}{ Concentration in exhaust gas*** } \\
\hline & & \multicolumn{2}{|c|}{$4 \times$ noise level } & \multicolumn{2}{|c|}{$2 \times$ blank level } \\
\hline & & $n g / 1$ & ppbv & $\mathrm{ng} / \mathrm{l}$ & ppbv \\
\hline Formaldehyde & 17 & 11 & 9 & 50 & 40 \\
\hline Acetaldehyde ${ }^{*}$ & 66 & 44 & 24 & 120 & 66 \\
\hline Propionaldehyde* & 180 & 120 & 50 & $\ldots$ & $\ldots{ }^{*}$ \\
\hline Acrolein & 47 & 31 & 13 & $\ldots$ & $\ldots * *$ \\
\hline Acetone & 33 & 13 & 9 & 43 & 30 \\
\hline
\end{tabular}

* based on smaller of two isomers

* no detectable blank level

** based on 15 I sample.

\section{Analysis}

As a rule, analysis followed within $\mathbf{2 4}$ hours after sampling. After heating at $60^{\circ} \mathrm{C}$ for $15 \mathrm{~min}$ to complete the reaction and cooling, the hydrazones are extracted with $3 \times 3 \mathrm{ml}$ portions of cyclohexane/toluene $5: 1(\mathrm{v} / \mathrm{v})$. The extracts are collected directly into $10 \mathrm{ml}$ volumetric flasks and made to $10 \mathrm{ml}$. The extracts were analyzed as soon as possible. Otherwise they were refrigerated after the addition of a crystal of DNPH.

Initially, we extracted the hydrazones with pure cyclohexane. Some hydrazones (notably, formaldehyde-DNPHzone), however, showed only poor solubility in this solvent, which caused problems when higher levels of aldehydes had to be sampled. Therefore, several other solvents and (azeotropic) mixtures of solvents were tested, such as ethylacetate, toluene, 1,1,1-trichloroethane, trichloroethane/ hexane, ethylacetate/hexane, cyclohexane/toluene. Of these a $5: 1(\mathrm{v} / \mathrm{v})$ mixture of cyclohexane and toluene performed best: the solubility of formaldehyde-DNPHzone in this solvent mixture is almost $1 \mathrm{mg} \mathrm{ml}^{-1}$, whereas DNPH was not extracted in any detectable amounts from a saturated solution in $2 \mathrm{M} \mathrm{HCl}$. It also performed will in the oncolumn injection technique.

$1 \mu$ of the extract was injected on-column for GC analysis, as described above. The aldehydes are quantified by ex- ternal calibration against standard mixtures. For carbonyl derivatives that form syn- and anti-isomers calculations are based on the sum of the area of both peaks (attempts were made to add underivatized cyclopentanone as an internal standard to the bubblers immediately before sampling. However, its recovery from the sampling solution was unsatisfactory).

Under these conditions minimum detectable amounts were established for the standard calibration mixtures as twice the noise level. In spite of all our efforts to purify the reagent and solvents, the DNPH sampling solution showed persistent blanks of formaldehyde, acetaldehyde, and acetone of about $15 \sim 38 \mathrm{ng} \mathrm{m}^{-1}$. Accounting for these impurities, the minimum detectable amounts must be established as twice the blank levels. The results are in Table III.

\section{Results and Discussion}

\section{Combustion Experiments}

The engine was run at three different air/fuel (A/F) ratios: lean, stoichiometric and rich. Sampling was started after sufficient warming up, when stable conditions were 
reached. Table IV gives the concentrations of some gases in the exhaust and the A/F ratios. The total amount of exhaust sampled was measured with a wet gas meter. In each case $15 \mathrm{I}$ (dry) exhaust gas was sampled.

\section{Results}

In the exhaust gases of the LP-gas fuelled test engine only formaldehyde, acetaldehyde, propionaldehyde, acrolein and acetone were found in measurable amounts (Fig. 4). Carbonyl compounds of more than $3 \mathrm{C}$-atoms were not detectable. Concentrations are reported in Table $V$ as ppmv

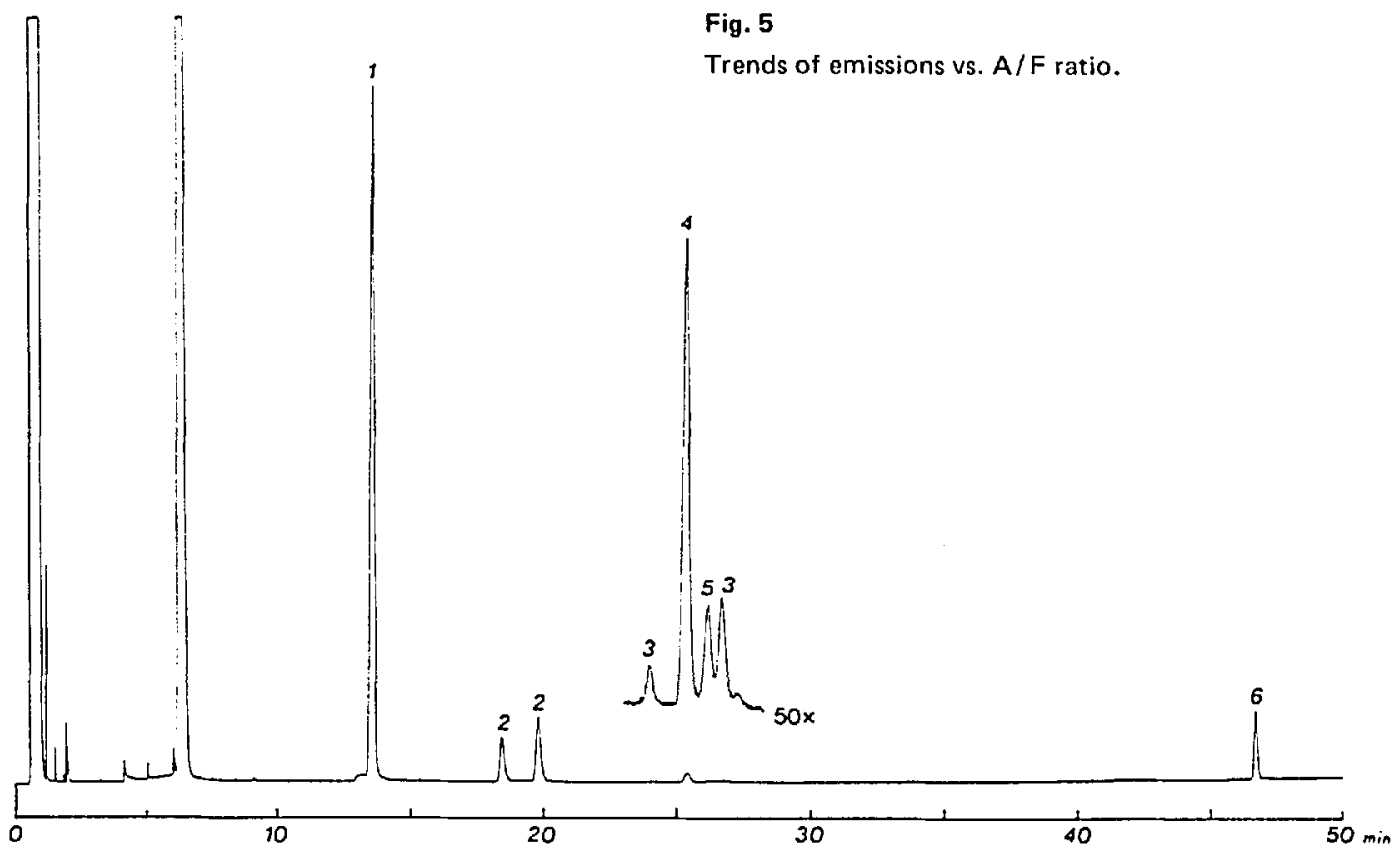

Fig. 4

Chromatogram of 151 exhaust gas, lean A/F ratio (for $G C$ conditions see text). $1=$ formaldehyde; $2=$ acetaldehyde; $\mathbf{3}$ = propionaldehyde; $\mathbf{4}$ = acetone: $\mathbf{5}=$ acrolein; $\mathbf{6}=$ cyclopentanone (i.s.).

Table IV. Concentrations of some gases in exhausts.

\begin{tabular}{|lccc|}
\hline & rich & stoichiometric & lean \\
\hline $\mathrm{CO}($ vol \%) & 2.35 & 0.91 & 0.03 \\
$\mathrm{CO}_{2}($ vol \%) & 12.0 & 12.8 & 12.7 \\
$\mathrm{O}_{2}($ vol \%) & 0.52 & 0.60 & 1.45 \\
$\mathrm{Hydrocarbons}$ as $\left(\mathrm{C}_{\mathrm{t}} \mathrm{H}_{14}\right)(\mathrm{ppm})$ & 118 & 120 & 95 \\
$\mathrm{NO}(\mathrm{ppm})$ & $(2980)^{*}$ & $(4250)^{*}$ & $(5860)^{*}$ \\
Air/Fuel ratio & 14.60 & 15.59 & 16.58. \\
$\lambda$ & 0.936 & 1.000 & 1.063 \\
\hline
\end{tabular}

* due to long supply lines NO concentrations are not correct. They are only for comparative purposes.

Table V. Concentration (ppmv) of aldehydes in exhaust gases of LPG fuelled engine.

\begin{tabular}{|lccc|}
\hline & rich & stoichiometric & lean \\
\hline Air/fuel ratio & 14.6 & 15.6 & 16.6 \\
Formaldehyde & 2.80 & 4.50 & 17.00 \\
Acetaldehyde & 1.30 & 1.60 & 2.90 \\
Propionaldehyde & 0.06 & 0.10 & 0.13 \\
Acrolein & 0.030 & 0.035 & 0.070 \\
Acetone & 0.17 & 0.18 & 0.27 \\
Sum of $\mathrm{C}_{1}-\mathrm{C}_{3}$ aldehydes & 4.20 & 6.25 & 20.1 \\
\hline
\end{tabular}


in dry exhaust gas. Fig. 5 shows the trends of exhaust emissions vs. A/F ratios.

In the first bubbler $>99 \%$ of the formaldehyde and $93 \sim 96 \%$ of the acetaldehyde was trapped. On the other hand one $3 \times 3 \mathrm{ml}$ extraction of the first bubbler yielded only $92 \sim 98 \%$ of the formaldehyde-DNPHzone, which made a second extraction necessary.

\section{Discussion}

The data in Table $V$ suggest increasing aldehyde concentrations with increasing $A / F$ ratios. Lean burning conditions are often used now to reduce $\mathrm{CO}$ and hydrocarbon emissions, and, if carried further, possibly also $\mathrm{NO}_{x}$ emissions. As discussed in the introduction, LP-gas fuelled engines are very attractive in this respect. In view of the fact that aldehydes are as photochemically reactive as olefinic hydrocarbons, the decrease of hydrocarbon emissions under lean burning conditions has to be balanced carefully against this possible increase of aldehyde emission.

\section{Conclusions}

It has been demonstrated that capillary GC with on-column injection and FID can be used with advantage to analyse 2,4-dinitro-phenylhydrazone derivatives of carbonyl compounds. Complete separation of the $\mathrm{C}_{3}$ carbonyls is possible, while GC detection levels are of the order of 20-50 pg (as free aldehydes). It is to be expected that these levels can be reduced substantially by the use of an ECD or NICIMS.

In combination with sampling using DNHP/2 $\mathrm{M} \mathrm{HCl}$ bubblers and cyclohexane/toluene extraction, carbonyl levels in the exhaust gas of about $10-40$ ppbv (15) sampling volume) can be detected without any concentration of the extract. In practice, however, the limits of detection are set by the attainable blank levels: in this study the blank levels limited the lower detectable concentrations to 30$70 \mathrm{ppbv}$. The method was well suited for the measurement of aldehydes in the exhaust gases of a LP-gas fuelled engine. The levels found are comparable to the lower levels found for gasoline and diesel vehicles (without catalytic exhaust control). However, levels tend to increase with increasing $A / F$ ratios i.e. with leaner combustion conditions. This clearly shows the necessity to measure and control aldehyde emissions beside other pollutants.

\section{References}

[1] R.W. Hurn, R.D. Fleming, J.R.Allsup; Preprints, Am. Chem. Soc., Div. Petr. Chem., 16, D52 (1971).

[2] J. van der Weide, NATO Comm. Challenges Mod. Soc. [Techn. Rep.] NATO/CCMS, 61, vol. 2, 727 (1978).

[3] P.E. Oberdorfer, SAE paper no. 670123 (1967).

[4] M.F. Fracchia, F.J. Schuette, P. K. Mueller; Environm. Sci. Technol., 1, 915 (1967).

[5] E.E. Wigg, R.J. Champion, W. L. Petersen, SAE paper no. 720251 (1972).

[6] K. Kuwata, M. Uebori, Y. Yamasaki, J. Chromatogr. Sci., 17, 264 (1979).
[7] L. Johnson, B. Josefsson, P. Mastorp; Int. J. Environm. Anal. Chem., 9, 7 (1981).

[8] F. Lipari, S. J. Swarin, J. Chromatogr., 247, 297 (1982).

[9] J.E. Sigsby, S. Tejada, W. Ray, J.W. Lang, J.W. Ducan, Environm. Sci. Techn., 21, 466 (1987).

[10] P.A. Gabele, J.O. Baugh, F. Black, R.Snow; J. Air Pollut. Control Soc., 35, 1168 (1985).

[11] S. J. Swarin, F. Lipari, J. Liq. Chromatogr., 6, 425 (1983).

[12] J.N. Braddock, P. A. Gabele; SAE paper no. 770168 (1977).

[13] G. Creech, R.T. Johnson, J. O. Stoffer, J. Chromatogr. Sci., 20,67 (1982).

[14] J.M. Perez, F. Lipari, D. E. Seizinger; SAE paper no. 840413 (1984).

[15] C. T. Hare, T. M. Baines; SAE paper no. 790424 (1979).

[16] M.A. Elliott, G. J. Nebel, F. G. Rounds, J. Air Pollut. Control Soc., 5, 103 (1955).

[17] M.C. Baxter, SAE paper no. 670054 (1967).

[18] R. C. Lee, D. B. Wimmer, SAE paper no. 680769 (1968).

[19] J. van der Weide, P. Tiedema, J.A.N. van Ling, "Alternative fuels with regard to LPG and methanol", 4th Int. Symp. Automotive Propulsion Syst., Washington DC, April 18-22, 1977.

[20] R.K. Beasley, C.E. Hoffmann, R.L. Rueppel, J.W. Worley, Anal. Chem., 52, 1110 (1980).

[21] D. Grosjean, K. Fung, Anal. Chem., 54, 1221 (1982).

[22] J.P. Guenier, P. Simon, J. Delcourt, M.F. Didierjean, $C$. Lefevre, J. Muller, Chromatographia, 18, 137 (1983).

[23] K. Kuwata, M. Uebori, H. Yamasaki, Y. Kuge, Y. Kiso, Anal. Chem., 55, 2013 (1983).

[24] P. Ciccioli, A. Cecinato, A. Liberti, in G. Angelotti \& G. Restrilli (Eds.) "Physico-chemical behaviour of atmospheric pollutants", Proc. 4th Eur. Symp., D. Reidel, Dordrecht, NL, 1987, p. 133.

[25] S. B. Tejada, Int. J. Environm. Anal. Chem., 26. 167 (1986).

[26] F. Lipari, S. J. Swarin, Environm. Sci. Techn., 19, 70 (1985).

[27] S. Selim, J. Chromatogr., 136, 271 (1977).

[28] K. Fung, D. Grosjean, Anal. Chem., 53, 168 (1981).

[29] V. Neitzert, W. Seiler; Geophys. Res. Lett., 8, 79 (1981).

[30] J.T. Graven, M.F. Giabbai, F.C. Pohland, Adv. Chem. Ser., 210, 43 (1985).

[31] H. van Duin, Ph. D. Thesis, Free University of Amsterdam, Amsterdam, 1961.

[32] V.P. Uralets, J.A. Rijks, P.A. Leclercq, J. Chromatogr., 194, 135 (1980).

[33] R.A. Smith, 1. Drummond, Analyst (London), 104, 875 (1979).

[34] D.C. Lowe, U.Schmidt, D.H. Ehhalt, "The tropospheric distribution of Formaldehyde", Report no. 1756, Kernforschungsanlage Jülich $\mathrm{GmbH}$, Jülich, FRG, Dec. 1981.

[35] D.C. Lowe, U. Schmidt, D.H. Ehhalt, C.G.B. Frischkorn, H.W. Nürnberg, Environm. Sci. Technol., 15, 819 (1981).

[36] B. Schubert, U.Schmidt, D.H. Ehhalt, in B. Versino and G. Angeletti (Eds.) "Physico-chemical behaviour of atmospheric pollutants", 3rd Eur. Symp., D. Reidel Publ. Co., Dordrecht, NL, 1984, 1984, p. 44.

[37] H. R. van Langenhove, M. van Acker, N. M. Schamp. Analyst (London), 108, 329 (1983).

[38] J.B. de Andrade, A. H. Miguel, Int. J. Environ. Anal. Chem. 21, 229 (1985).

[39] S.Dong, P.K. Dasgupta, Environ. Sci Technol., 20, 637 (1986).

[40] J.F. Walker, "Formaldehyde", 3rd ed., R.E. Kriegel Publ. Co., New York, 1975, p. 53.

[41] J.L. Kurtz, J. Am. Chem. Soc., 89, 3524 (1967).

[42] R.L.Shriner, R.C. Fuson, D. Y. Curtin, T.C. Morill: "The systematic identification of organic compounds", 6th Ed., John Wiley \& Sons, New York, 1980.

Received: Sep, 27, 1988 Accepted: Nov, 3, 1988 G 